\title{
Control of Phytophthora cryptogea in the hydroponic forcing of witloof chicory with the rhamnolipid-based biosurfactant formulation PRO1
}

\author{
K. De Jonghe ${ }^{a *}$ †, I. De Dobbelaere ${ }^{a}$, R. Sarrazyn ${ }^{b}$ and M. Höfte ${ }^{a}$ \\ ${ }^{a}$ Ghent University Laboratory of Phytopathology, Coupure Links 653, B-9000 Ghent; and ${ }^{\mathrm{b}}$ Provincial Research and Advisory Centre for \\ Agriculture and Horticulture (POVLT), leperseweg 87, B-8800 Rumbeke-Beitem, Belgium
}

Rhamnolipids, extracellular metabolites of Pseudomonas aeruginosa with surfactant properties, proved to be very effective in controlling the spread of brown root rot disease caused by Phytophthora cryptogea in the hydroponic forcing system of witloof chicory (Cichorium intybus var. foliosum). The biosurfactant was applied as the product PRO1, a formulation of $25 \%$ rhamnolipids in oil. Both an in vitro screening and in vivo experiments in a mini-hydroponic system demonstrated the ability of PRO1 to control brown root rot. A $25 \mu \mathrm{g} \mathrm{mL} \mathrm{m}^{-1}$ rhamnolipids nutrient solution was enough to obtain good control of an artificial infection with a zoospore suspension of $P$. cryptogea. The biosurfactant PRO1 per-

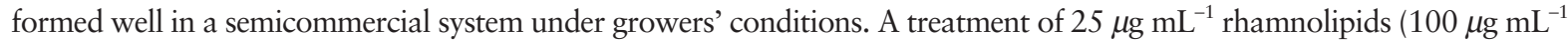
PRO1) reduced the disease incidence significantly in two independent experiments. However, PRO1 was not effective when a mycelial suspension was used as inoculum. Rhamnolipids have good potential to limit the spread of $P$. cryptogea in the hydroponic forcing system of witloof chicory, and can be used as a preventive measure against brown root rot.

Keywords: biological control, Cichorium intybus var. foliosum, Pseudomonas aeruginosa, soil-free growing system, zoosporic pathogens

\section{Introduction}

Witloof chicory (Cichorium intybus var. foliosum) is an important vegetable crop in Belgium, France and the Netherlands. The crop, also called Belgian endive, refers to the blanched, tight heads produced by placing (in darkness) big mature chicory roots in forcing structures. Nowadays, the forcing of the crop usually takes place in a hydroponic system.

Phytophthora cryptogea is a zoospore-producing pathogen that causes an important root rot disease of witloof chicory (Forlot et al., 1966; Stanghellini \& Kronland, 1982). The pathogen is normally brought into the recirculating system via field soil adhering to the roots or via roots with latent infections. Once the pathogen is introduced into such a cultural system, its control is often difficult and commonly requires the shutdown and disinfestation of the entire system (Stanghellini et al., 1996b). Early detection and immediate proper action are therefore very important. Currently, effective detection

*To whom correspondence should be addressed.

†E-mail: kris.dejonghe@ugent.be

Accepted 10 October 2004 methods for $P$. cryptogea in a hydroponic system are available (Pettitt et al., 2002), but control measures are still traditional using commonly registered pesticides such as fosetyl-aluminium, propamocarb hydrochloride and dimethomorph.

Tomlinson \& Faithfull (1979; 1980), Stanghellini \& Miller (1997) and Demeulenaere \& Höfte (2000) have shown that surfactants can exhibit a lytic activity against zoospores. The effectiveness of surfactants as practical control agents for root-infecting zoosporic plant pathogens in hydroponic systems has been demonstrated by Stanghellini \& Rasmussen (1994) and Stanghellini et al. (1996a,b, 2000). Surfactants are surface-active compounds capable of reducing surface and interfacial tension at the interfaces between liquids, solids and gases, thereby allowing them to mix or disperse readily as emulsions in water or other liquids (Banat et al., 2000). Microorganisms produce a variety of surface-active agents (biosurfactants). Biosurfactants have a hydrophilic portion, consisting of mono-, oligo- or polysaccharides, amino acids, peptides, carboxylate or phosphate groups, and a hydrophobic portion, which is composed of saturated or unsaturated hydroxyl (fatty) acids or fatty alcohols (Lang \& Wullbrandt, 1999). These biosurfactants can be further divided into low-molecular-weight molecules that lower 
surface and interfacial tensions efficiently and highmolecular-weight polymers that bind tightly to surfaces (Ron \& Rosenberg, 2001). Tensio-active glycolipids containing one (mono-rhamnolipid) or two (di-rhamnolipid) L-rhamnose molecules and $\beta$-hydroxydecanoic acid are called rhamnolipids (Rahim et al., 2001).

The use of biosurfactant-producing organisms in the control of plant diseases in general, and zoosporic plant pathogens in particular, has not been extensively studied. Nielsen et al. (1998, 1999, 2002), Nielsen \& Sørensen (2003) and Thrane et al. (2000) reported a cyclic lipopeptide, viscosinamide, produced by a Pseudomonas fluorescens strain with surfactant and antifungal properties, while de Souza et al. (2003) described Ps. fluorescens strains that produce surfactants with lytic activity against zoospores of several oomycetes. Stanghellini \& Miller (1997) evaluated the potential of various rhamnolipidproducing fluorescent Pseudomonas spp. in the control of $P$. capsici on peppers grown in hydroponic units. In a recent study on the biological control of Pythium aphanidermatum in soil-free systems, Folman et al. (2003) studied the role of biosurfactants in the control of various oomycete pathogens by Lysobacter enzymogenes.

In this work, the capacity of a selected biosurfactant formulation PRO1, containing rhamnolipids from Ps. aeruginosa, is evaluated to control Phytophthora root rot in witloof chicory hydroponic forcing.

\section{Materials and methods}

\section{Plant material}

Witloof chicory (C. intybus var. foliosum) cultivars used in this study were Vintor and Platine. There is no difference in disease resistance against $P$. cryptogea brown root rot between these cultivars. Organically grown roots were supplied by the Provincial Research and Advisory Centre for Agriculture and Horticulture, POVLT RumbekeBeitem, Belgium, and stored at $0-1^{\circ} \mathrm{C}$ until use.

\section{Pathogen}

Phytophthora cryptogea strain no. PD2009, isolated from witloof chicory, was supplied by 'Plantenziektenkundige Dienst', Wageningen, the Netherlands. Axenic cultures of the strain were grown in darkness at $24^{\circ} \mathrm{C}$ on $\mathrm{V} 8$ juice agar [V8A; 200 mL V8-juice (Campbell Foods Belgium, Puurs, Belgium), 15 g agar (Pulvis; Federa, 1130 Brussels, Belgium), $2 \mathrm{~g} \mathrm{CaCO}_{3}$ and $800 \mathrm{~mL}$ distilled water].

\section{Zoospore production}

Zoospores were produced under aseptic conditions using a modification of the procedure described by Chen $\&$ Zentmyer (1970). Ten 5-mm agar plugs were transferred from the leading edge of a 4-day-old colony to a $90-\mathrm{mm}$ diameter Petri dish containing $15 \mathrm{~mL}$ sterile mineral salt solution $\left(0 \cdot 145 \mathrm{~g} \mathrm{Ca}\left(\mathrm{NO}_{3}\right) \cdot 4 \mathrm{H}_{2} \mathrm{O}, 0 \cdot 012 \mathrm{~g} \mathrm{MgSO}_{4} \cdot 7 \mathrm{H}_{2} \mathrm{O}\right.$, $0.099 \mathrm{~g} \mathrm{KH}_{2} \mathrm{PO}_{4}$ and $0 \cdot 016 \mathrm{~g} \mathrm{FeCl}_{3} \cdot 6 \mathrm{H}_{2} \mathrm{O}$ in $1 \mathrm{~L}$ of distilled water autoclaved for $15 \mathrm{~min}$ at $121^{\circ} \mathrm{C}$ ). The Petri dishes were then kept under continuous light at $22^{\circ} \mathrm{C}$ to induce sporangia formation. After $72 \mathrm{~h}$, the plates were kept at $4^{\circ} \mathrm{C}$ for $1 \mathrm{~h}$ followed by $1 \mathrm{~h}$ incubation at room temperature to induce a synchronized zoospore release. The zoospore suspension from each dish was harvested. The plates were rinsed with cold $\left(4^{\circ} \mathrm{C}\right)$ sterile distilled water. This water was collected in the same tubes containing the zoospore suspension from the corresponding Petri dish. The inoculum concentration was adjusted by diluting the obtained zoospore suspension to a final concentration of $10^{2}$ or $10^{3}$ zoospores per $\mathrm{mL}$ nutrient solution.

\section{Surfactant}

The biosurfactant PRO1 consists of a formulation of $25 \%$ rhamnolipids (extracted from the bacterium Ps. aeruginosa) in oil, and was supplied by Plantsupport (the Netherlands). Concentrations of 12.5 and $25 \mu \mathrm{g} \mathrm{mL}^{-1}$ rhamnolipids (50 and $100 \mu \mathrm{g} \mathrm{mL}^{-1}$ PRO1, respectively) were used in the experiments.

In a pot assay, the surfactant was only added at the beginning of the experiment, whereas for experiments in a hydroponic system, the surfactant applications were given at the beginning of the experiment and repeated after 1 week. Preliminary studies showed that PRO1 at $100 \mu \mathrm{g} \mathrm{mL}^{-1}$ was not phytotoxic (data not shown).

\section{In vivo assays for surfactant testing}

Pot assays

Organically grown witloof chicory roots (cv. Vintor) were harvested, stored and prepared for the forcing phase in standardized optimal conditions. The roots were individually placed in pots $(10 \times 10 \times 12 \mathrm{~cm})$ and each pot was filled with $500 \mathrm{~mL}$ nutrient solution consisting of $0.46 \mathrm{~g} \mathrm{~L}^{-1}$ $\mathrm{KNO}_{3}, 0.35 \mathrm{~g} \mathrm{~L}^{-1} \mathrm{MgSO}_{4} \cdot 7 \mathrm{H}_{2} \mathrm{O}, 1 \cdot 00 \mathrm{~g} \mathrm{~L}^{-1} \mathrm{Ca}\left(\mathrm{NO}_{3}\right)_{2} \cdot 4 \mathrm{H}_{2} \mathrm{O}$, $0 \cdot 21 \mathrm{~g} \mathrm{~L}^{-1} \mathrm{KH}_{2} \mathrm{PO}_{4}$ and $0 \cdot 30 \mathrm{~g} \mathrm{~L}^{-1} \mathrm{~K}_{2} \mathrm{SO}_{4}$ diluted in distilled water. In the pot experiments, an inoculum of two zoospore concentrations $\left(10^{2}\right.$ and $\left.10^{3} \mathrm{~mL}^{-1}\right)$ of P. cryptogea and a control were combined with three surfactant treatments: 0,50 and $100 \mu \mathrm{g} \mathrm{mL}^{-1}$ PRO1. In each pot experiment, eight replications per treatment were arranged in a complete randomized block design $(8 \times 3 \times 3)$. In each experiment, infected and healthy control treatments were included. All experiments were conducted in the dark at an air temperature of $18 \pm 2^{\circ} \mathrm{C}$. Disease incidence ( $\%$ diseased roots) and disease severity (mean lesion length in $\mathrm{cm}$ ) were recorded 14 days after inoculation.

\section{Mini-hydroponic system}

Organically grown witloof chicory roots (cv. Vintor) were harvested, stored and prepared for the forcing phase in standardized optimal conditions. Twenty-four witloof chicory roots were equally divided over three levels in a mini-hydroponic system (Fig. 1). The container size in the mini-hydroponic system was $40 \times 60 \mathrm{~cm}$ and had an overflow system at a height of $5 \mathrm{~cm}$. The mini-hydroponic system contained $60 \mathrm{~L}$ recirculating nutrient solution $(\mathrm{cfr}$. 


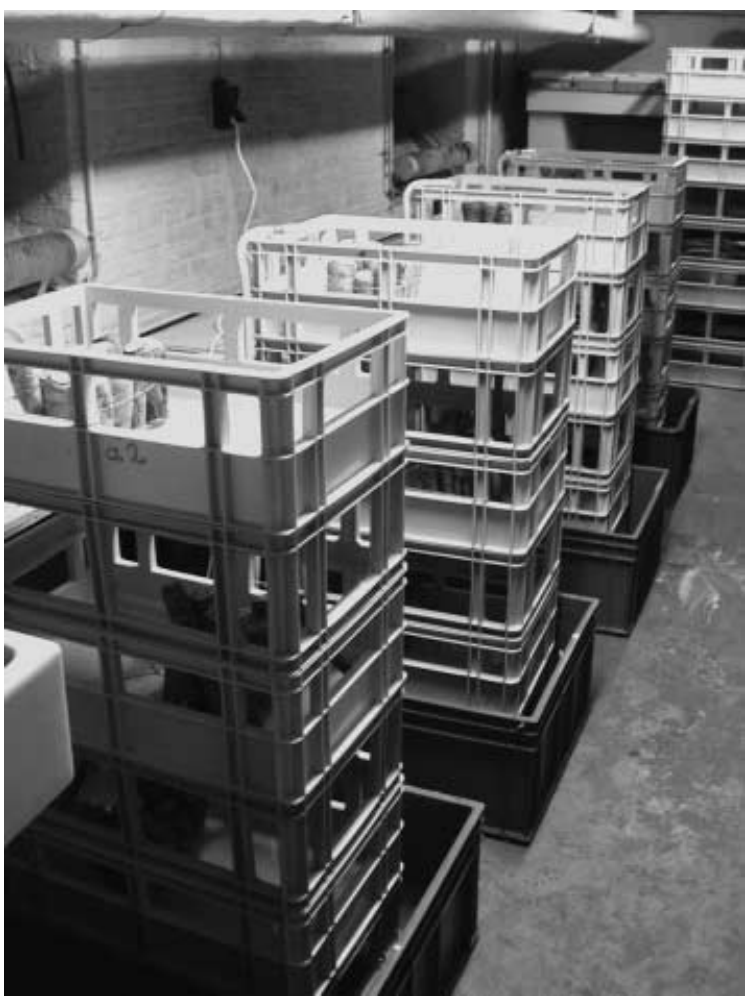

Figure 1 Mini-hydroponic system for forcing witloof chicory roots.

pot assays). For the infection, an inoculum density of $10^{2}$ zoospores of $P$. cryptogea was used. PRO1 was applied in concentrations of 50 and $100 \mu \mathrm{g} \mathrm{mL}^{-1}$. In each experiment, uninoculated and inoculated control treatments were included. All experiments were conducted in the same conditions as the pot experiments, and disease incidence ( $\%$ diseased roots) and disease severity (mean lesion length in $\mathrm{cm}$ ) were recorded 14 days after the start of the experiment. Water flow rate in the mini-hydroponic system was $200 \mathrm{~L} \mathrm{~h}^{-1}$. The experiments in the mini-hydroponic setup were carried out with an application of the surfactant at the start of the experiment and a repetition after 7 days. Infection with the pathogen was done with a single addition of the inoculum at the start of the experiment. The experiment was repeated.

Hydroponic forcing system 'bain-marie' type (Fig. 2)

Two standardized experiments in a semicommercial system under good experimental practice (GEP) regulations were carried out at the Provincial Research and Advisory Centre for Agriculture and Horticulture in RumbekeBeitem, Belgium. Organically grown witloof chicory roots were harvested, stored and prepared for the forcing phase in standardized optimal conditions.

In the first experiment, treatments included an uninoculated control treatment, an inoculated treatment and an inoculated treatment in which the nutrient solution was amended with $100 \mu \mathrm{g} \mathrm{mL} \mathrm{m}^{-1}$ PRO1. Water and air temperature were set at $15^{\circ} \mathrm{C}$. Roots of cv. Platine were used. The storage period was 4 months.

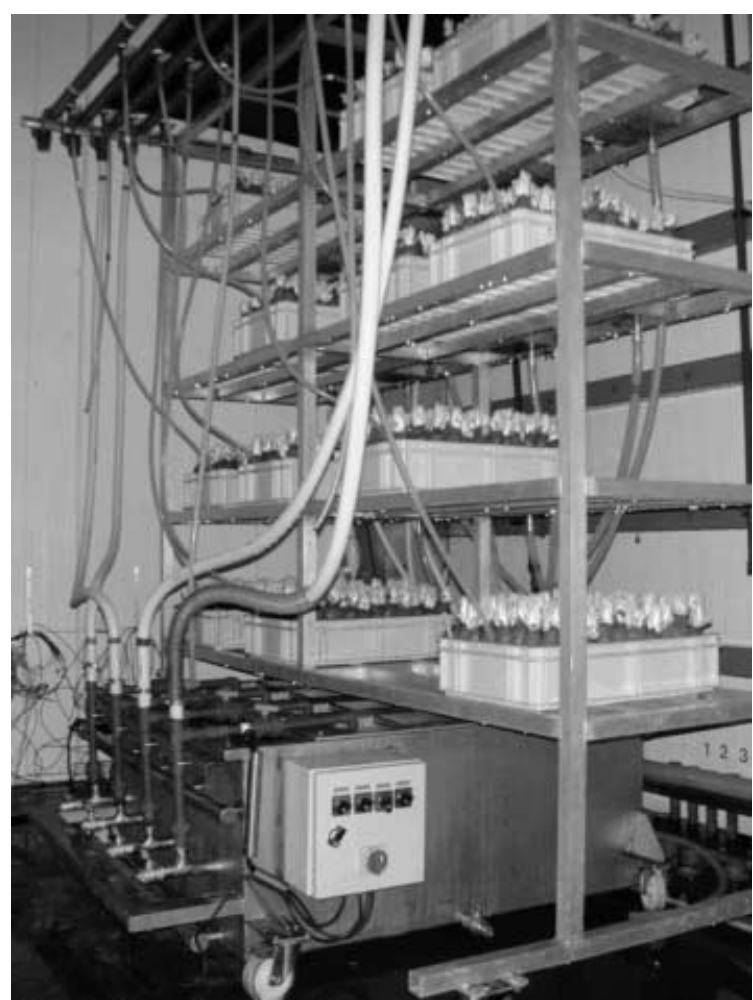

Figure 2 Hydroponic system - 'bain-marie' type for forcing witloof chicory roots.

A second experiment included an uninoculated control treatment, an inoculated control treatment, an inoculated treatment amended with $100 \mu \mathrm{g} \mathrm{mL}^{-1}$ PRO1 and an inoculated treatment with an extra 10 diseased roots per tray, amended with $100 \mu \mathrm{g} \mathrm{mL} \mathrm{m}^{-1}$ PRO1. Water and air temperature were set at $17^{\circ} \mathrm{C}$. Roots of cv. Vintor were used. The storage period was 4 months.

Infection was carried out with $10^{2}$ zoospores of P. cryptogea per $\mathrm{mL}$ nutrient solution. Each treatment was carried out in four levels of $40 \times 60 \mathrm{~cm}$ containers containing $\sim 100$ roots. The closed recirculating system contained 60 $\mathrm{L}$ of nutrient solution (content in $\mathrm{mmol} \mathrm{L}^{-1}: \mathrm{K}^{+}, 8 \cdot 0 ; \mathrm{Mg}^{2+}$, 1.4; $\mathrm{Ca}^{2+}, 4 \cdot 2 ; \mathrm{NO}_{3}^{-}, 13 \cdot 7 ; \mathrm{PO}_{4}^{-}, 1 \cdot 5$ and $\left.\mathrm{SO}_{4}^{-}, 2 \cdot 0\right)$. Electric conductivity during the experiment was held constant at $2 \pm 0 \cdot 2 \mathrm{mS} \mathrm{cm}^{-1}$ and $\mathrm{pH}$ was set between $6 \cdot 5$ and $7 \cdot 5$. The amount of nutrient solution in each container was constant by means of an overflow $(5 \mathrm{~cm}$ high) to the underlying level. The reservoirs of each closed system (one for each treatment) were placed in the same water tank (total volume $1000 \mathrm{~L}$ ) buffering the water temperature in all treatments (bain-marie system, Fig. 2). Water flow rate was set at $500 \mathrm{~L} \mathrm{~h}^{-1}$. Nineteen days after placing the roots in the forcing trays, disease incidence $(\%)$, yield $(\mathrm{kg})$ and standard quality characteristics [size, compactness, shape, colour and physiological disorders (internal browning)] of the harvested crop were recorded. Biological efficiency $(\%)$, which is output (yield in $\mathrm{kg}$ ) divided by input (average root weight in $\mathrm{kg}$ ) was calculated.

The date of harvesting was determined by crop maturity and commercial considerations. 


\section{Statistical data analysis}

Statistical analysis of data was performed using the software package SPSS $11 \cdot 0 \cdot 1$. (SPSSinc, Chicago, IL, USA). For the nominal data of disease severity (lesion length in $\mathrm{cm}$ ) the conditions of normality and homogeneity of variances were not fulfilled and a suitable transformation was not available. For these data sets, the nonparametric Kruskal-Wallis and Mann-Whitney tests were performed and $\alpha$-values were corrected for multiple comparisons. For the ordinal disease incidence data, a logistic regression analysis was performed. Interaction between the different factors was checked.

\section{Results}

\section{In vitro experiments}

The biosurfactant concentrations used in this study were selected after an initial in vitro screening experiment at a wide concentration range. A significant reduction of sporangia formation and general zoospore lysis (within $1 \mathrm{~min}$ after surfactant application) was obtained at a minimal concentration of $50 \mu \mathrm{g} \mathrm{mL}{ }^{-1}$ PRO1. Amendment of a solid medium with different concentrations $\left(0-5 \mathrm{mg} \mathrm{mL}^{-1}\right)$ of PRO1 had limited effects on the mycelial growth of P. cryptogea (data not shown). Preliminary studies also showed that PRO1 at $100 \mu \mathrm{g} \mathrm{mL}^{-1}$ was not phytotoxic (data not shown).

\section{Pot assays}

The infected control treatments only showed a concentration effect for disease severity, and not for disease incidence. An infection with $10^{3}$ zoospores $\mathrm{mL}^{-1}$ resulted in $87.5 \%$ diseased roots and a mean lesion length of $7.0 \mathrm{~cm}$, compared with an identical disease incidence and a mean lesion length of $3.8 \mathrm{~cm}$ at the lower infection pressure of $10^{2}$ zoospores. In the uninfected control treatment, $12.5 \%$ of the roots showed phytophthora root rot symptoms with a mean lesion length of $0.4 \mathrm{~cm}$ in the roots with brown root rot symptoms (Fig. $3 \mathrm{a}$ and b). Adding $50 \mu \mathrm{g}$ $\mathrm{mL}^{-1}$ PRO1 to the pots at a disease pressure of $10^{2}$ zoospores $\mathrm{mL}^{-1}$ also resulted in $12.5 \%$ diseased roots and a mean lesion length of $5 \cdot 2 \mathrm{~cm}$. Increasing the surfactant concentration to $100 \mu \mathrm{g} \mathrm{mL}^{-1}$ at the same disease pressure resulted in $25 \%$ of the roots with brown root rot symptoms and a mean lesion length in the diseased roots of only $0.7 \mathrm{~cm}$ (Fig. 3a and b).

At a higher disease pressure of $10^{3}$ zoospores $\mathrm{mL}^{-1}, 75$ and $37.5 \%$ diseased roots were recorded for treatments with 50 and $100 \mu \mathrm{g} \mathrm{mL}^{-1}$ PRO1, respectively (Fig. 3a). The mean lesion length in the roots with disease symptoms for both treatments was significantly reduced to $2 \cdot 4$ and $1.7 \mathrm{~cm}$, respectively (Fig. $3 \mathrm{~b}$ ).

Experiments were repeated with similar results, except for disease severity at the $10^{2}$ zoospores $\mathrm{mL}^{-1}$ level (Fig. 3d). For this treatment, no diseased roots at all were recorded in repetition 2 (Fig. $3 \mathrm{c}$ and $\mathrm{d}$ ), while in repetition
1 the few diseased roots were heavily infested, resulting in relatively high mean lesion length (Fig. $3 a$ and b).

In another series of pot experiments, different concentrations of mycelium suspension of P. cryptogea were used as inoculum. Only a limited effect on both disease incidence and disease severity was seen after application of PRO1 at a concentration of 50 or $100 \mu \mathrm{g} \mathrm{mL}^{-1}$ (data not shown).

\section{Mini-hydroculture assay}

Adding 50 or $100 \mu \mathrm{g} \mathrm{mL} \mathrm{m}^{-1}$ PRO1 to a mini-hydroponic system infected with $10^{2}$ P. cryptogea zoospores $\mathrm{mL}^{-1}$, reduced the disease incidence significantly from $91.6 \%$ to 50.0 or $29.2 \%$, respectively (Fig. 4 a, repetition 1 ). A mean lesion length of $3.8 \mathrm{~cm}$ in the diseased roots of the infected control was recorded (Fig. 4b, repetition 1). Amendment with 50 or $100 \mu \mathrm{g} \mathrm{mL}^{-1}$ PRO1 reduced the mean lesion length in the diseased roots significantly to an average of 1.0 or $0.8 \mathrm{~cm}$, respectively. This was not significantly different from the healthy control $(0 \cdot 8 \mathrm{~cm})$.

The experiment was repeated with similar results, except for a much higher mean lesion length for the $100 \mu \mathrm{g} \mathrm{mL}^{-1}$ PRO1 treatment. The disease incidence in repetition 2 was very low for this treatment, but the few diseased roots were severely affected, resulting in a high disease severity (Fig. $4 \mathrm{a}$ and b, repetition 2).

An experiment with a single application of the surfactant at start-up did not reduce the disease incidence and severity significantly (data not shown).

\section{Hydroponic forcing system 'bain-marie' type}

In a first experiment in semicommercial conditions, the disease incidence in the inoculated control was only $16 \cdot 3 \%$. The inoculated treatment with two weekly applications of $100 \mu \mathrm{g} \mathrm{mL}^{-1}$ PRO1 resulted in only three diseased roots out of a total of $400(0.8 \%)$. This was not significantly different from the uninoculated control containing one diseased root $(0 \cdot 3 \%)$ (Table 1 , experiment 1 ).

The experiment was repeated with a higher air and water temperature and disease incidence increased to $79.1 \%$ in the inoculated treatment. Only $5.5 \%$ of the roots showed symptoms of a P. cryptogea infection in a treatment with zoospore infection and $100 \mu \mathrm{g} \mathrm{mL}^{-1}$ PRO1. In the uninfected control, $1.7 \%$ of the roots showed disease symptoms. In the infected control treatment, a significant reduction in yield $(\mathrm{kg})$ and biological efficiency $(\%)$ was observed. The PRO1 treatment did not result in significant yield differences with the uninfected control treatment (Table 1). No significant differences between the different tray levels were observed (data not shown). In the same experiment, a treatment with zoospore infection, $100 \mu \mathrm{g} \mathrm{mL}^{-1}$ PRO1 and an extra 10 diseased roots per tray resulted in $46.4 \%$ of the roots with disease symptoms. This is significantly higher than a PRO1 treatment with only a zoospore infection in the nutrient solution. In this treatment, it was observed that mainly roots in direct contact with the diseased roots developed disease symptoms. Additionally, disease can also spread by contact between 

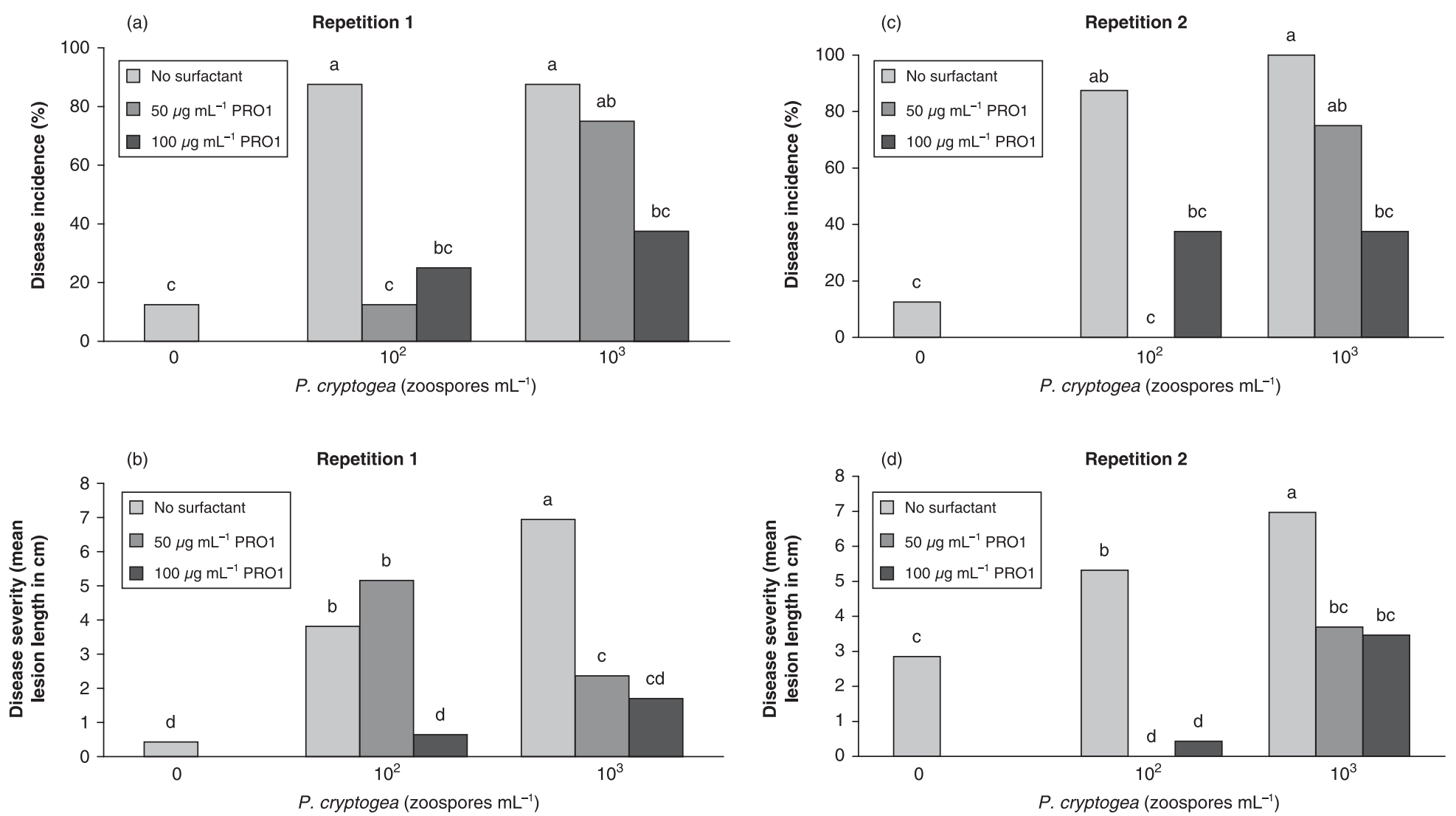

Figure 3 Disease incidence $(\%)(a, c)$ and disease severity (mean lesion length of the diseased roots in $\mathrm{cm}$ ) $\left(\mathrm{b}, \mathrm{d}\right.$ ) in pot assays for treatments with 50 and $100 \mu \mathrm{g} \mathrm{mL}^{-1} \mathrm{PRO} 1$ and two different infection levels of Phytophthora cryptogea $\left(1 \times 10^{2}\right.$ and $1 \times 10^{3}$ zoospores $\left.\mathrm{mL}^{-1}\right)$. 
(a)

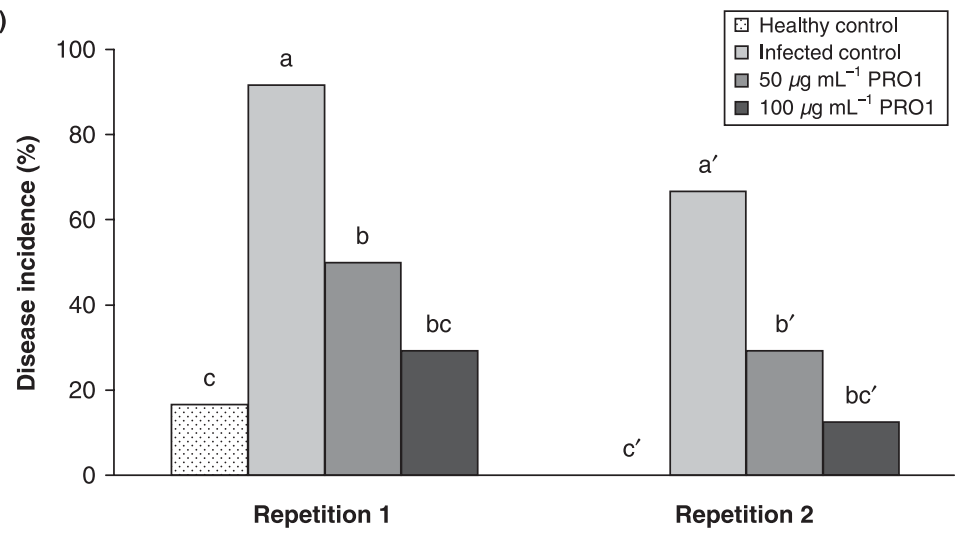

(b)

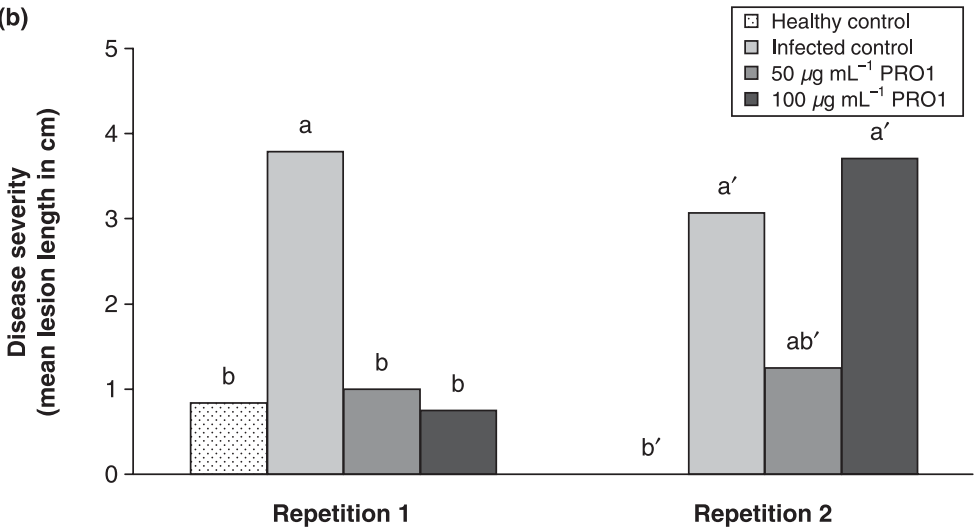

Figure 4 Disease incidence (\%) (a) and disease severity (mean lesion length of the diseased roots in $\mathrm{cm}$ ) (b) in a mini-hydroponic system for treatments with 50 and $100 \mu \mathrm{g} \mathrm{mL}^{-1}$ PRO1 and infection level of $1 \times 10^{2}$ zoospores Phytophthora cryptogea per $\mathrm{mL}$

Table 1 Disease incidence $(\%)$, yield $(\mathrm{kg})$, average root weight $(\mathrm{kg})$ and biological efficiency $(\%)$ in a hydroponic system under semicommercial conditions following infection with $1 \times 10^{2}$ zoospores $\mathrm{mL}^{-1}$ of Phytophthora cryptogea. PRO1 (100 $\left.\mu \mathrm{g} \mathrm{mL}^{-1}\right)$ was applied at the start of the experiment and the application was repeated after 7 days. For each experiment, values followed by the same letter are not significantly different at $P=0.05$

\begin{tabular}{|c|c|c|c|c|c|c|}
\hline & Treatment & $\begin{array}{l}\text { Total no. } \\
\text { of roots }\end{array}$ & Yield (kg) & $\begin{array}{l}\text { Root } \\
\text { weight (kg) }\end{array}$ & $\begin{array}{l}\text { Biological } \\
\text { efficiency (\%) }\end{array}$ & $\begin{array}{l}\text { Disease } \\
\text { incidence (\%) }\end{array}$ \\
\hline \multirow[t]{3}{*}{ Experiment $1^{a}$} & Healthy control & 400 & $46 \cdot 6 \mathrm{a}$ & $74.5 \mathrm{a}$ & $62.5 \mathrm{a}$ & $0 \cdot 3 b$ \\
\hline & Infected control & 400 & $46 \cdot 2 \mathrm{a}$ & $77 \cdot 1 \mathrm{~b}$ & $60 \cdot 0 \mathrm{~b}$ & $16 \cdot 3 a$ \\
\hline & Infection + PRO1 & 400 & $47 \cdot 6 a$ & $75 \cdot 0 \mathrm{a}$ & $63.5 \mathrm{a}$ & $0.8 b$ \\
\hline \multirow[t]{3}{*}{ Experiment 2} & Healthy control & 419 & $48.5 \mathrm{~A}$ & $74 \cdot 2 \mathrm{~A}$ & $65 \cdot 4 \mathrm{~A}$ & $1 \cdot 7$ в \\
\hline & Infected control & 406 & 44.5 в & $72.9 \mathrm{~A}$ & $61 \cdot 1$ в & $79 \cdot 1$ A \\
\hline & Infection + PRO1 & 402 & $48 \cdot 0 \mathrm{~A}$ & $74 \cdot 4 \mathrm{~A}$ & $64.5 \mathrm{~A}$ & $5 \cdot 5$ в \\
\hline
\end{tabular}

a Water and air temperature was $15^{\circ} \mathrm{C}$ in experiment 1 , and $17^{\circ} \mathrm{C}$ in experiment 2 .

diseased and healthy roots above the water level, where there is no contact with the applied rhamnolipids. Unfortunately, because of technical limitations (the system can only carry a maximum of four treatments), an inoculated control treatment including diseased roots at the start of the experiment could not be included.

\section{Discussion}

This study shows that rhamnolipids have the potential to be used in the control of brown root rot caused by P. cryptogea in the hydroponic forcing of witloof chicory.
The in vitro screening results confirm the results from Stanghellini \& Miller (1997), who found zoosporicidal activity of purified mono- and di-rhamnolipids against $P$. capsici, Pythium aphanidermatum and Plasmopara lactucaeradicis at concentrations ranging from 5 to $30 \mu \mathrm{g} \mathrm{mL}^{-1}$. A range of synthetic surfactants were screened by Demeulenaere \& Höfte (2000) on their in vitro effects on mycelium growth, sporangia formation and zoospore survival. Their results show significant effects of some surfactants on mycelium growth of P. cryptogea from $100 \mu \mathrm{g} \mathrm{mL}^{-1}$ onwards, and effects on sporangia formation and zoospore production for most surfactants included in the experiments at a concentration as low as 10 or $20 \mu \mathrm{g} \mathrm{mL}^{-1}$. 
In vivo, in all types of experiments, the use of untreated, organically grown witloof chicory roots led to a certain disease level in the uninfected control. This is most likely caused by a natural pathogen infection brought in with the roots from the field.

A good control of the pathogen was obtained with $25 \mu \mathrm{g} \mathrm{mL}^{-1}$ rhamnolipids nutrient solution. This also corresponds with the results of Stanghellini \& Miller (1997) who used rhamnolipid-producing Pseudomonas strains to control $P$. capsici root rot in a hydroponic system. They observed a significant reduction of the disease symptoms at an estimated quantity of $8-10 \mu \mathrm{g} \mathrm{mL}^{-1}$ rhamnolipids. The growth and maintenance of a critical bacteria concentration in such a system, however, require the addition of a Csource to the nutrient solution. Moreover, the regulation of rhamnolipid production in Pseudomonas spp. is subject to quorum sensing (Rahim et al., 2001) and is partially dependent on RpoS, the sigma factor of the stationary phase (Medina et al., 2003). These problems can be avoided by using pure rhamnolipids rather than rhamnolipid-producing bacteria. Kim et al. (2000) also used pure rhamnolipids to control Phytophthora blight in pepper-growing fields. However, leaves and stems of pepper had to be sprayed with a concentration of $500 \mu \mathrm{g} \mathrm{mL}^{-1}$ rhamnolipids to obtain a similar control level as obtained with conventional fungicides.

In the present work, one application of rhamnolipids was not sufficient. This corresponds with studies of Stanghellini et al. (1996a,b) where fast surfactant degradation was observed and re-application was indispensable. Since a forcing cycle of witloof chicory only takes about 2-3 weeks, the biosurfactant treatments can be limited to two applications.

The low disease level $(16 \cdot 3 \%)$ in the infected control of the first semicommercial GEP experiment could be due to the low water and air temperatures (both held constant at $15^{\circ} \mathrm{C}$ ). In the second semicommercial experiment, in which the water and air temperatures were increased to $17^{\circ} \mathrm{C}$, the disease incidence in the infected control was $79 \cdot 1 \%$. A temperature of $18 \pm 2^{\circ} \mathrm{C}$ always resulted in a high disease incidence in the mini-hydroponic system.

The two experiments in the semicommercial system were carried out with witloof chicory roots that had been stored at $0-1^{\circ} \mathrm{C}$ for 4 months. This may also have played a role, since no problems with artificial infection for similar experiments with synthetic surfactants were seen at lower forcing temperatures $\left(15^{\circ} \mathrm{C}\right)$ when roots were used which came straight from the field or underwent only a short storage period (KDJ et al., unpublished data).

Rhamnolipids only had a limited effect on mycelium development (in vitro screening results, data not shown). This was confirmed through in vivo experiments. PRO1 was not able to control brown root rot disease following an artificial infection with mycelial suspensions of $P$. cryptogea. Additionally, a treatment including $~ 10 \%$ diseased roots in the system showed that a large part of the efficiency of the biosurfactant was lost. Diseased roots could still spread the disease to healthy roots in direct contact, most likely through mycelium, also because part of the contact zone between diseased and healthy tissue is situated above the water level.

Rhamnolipids thus mainly act against the zoospore stage of the pathogen. It has been observed, however, that the synthetic surfactant Atplus MBA1301, an alcohol alkoxylate, is able to control infections with both mycelium and zoospore suspensions of P. cryptogea (KDJ et al., unpublished data).

In conclusion, application of $25 \mu \mathrm{g} \mathrm{mL}^{-1}$ rhamnolipids nutrient solution controls the spread of zoospores in the system (preventive control), but once the pathogen is introduced in the root, only a limited effect on the outgrowth of the pathogen is obtained (curative control). In practice, however, zoospores are the most important infection structures in hydroponic growing systems. Rhamnolipids, with their molecular structure of hydrophilic head and lipophilic tails, most likely disrupt the outer membrane of the zoospore cell (which lacks a cell wall) due to intercalation into the membrane (Stanghellini \& Miller, 1997; Kim et al., 2000).

Future studies now focus on the use of surfactants in the control of Phytophthora diseases in tomato culture in rock wool slabs and the possible effects surfactants may have on the root tissue.

\section{Acknowledgement}

The authors thank Plantsupport (the Netherlands) for providing the biosurfactant used in the present study.

\section{References}

Banat IM, Makkar RS, Cameotra SS, 2000. Potential commercial applications of microbial surfactants. Applied Microbiology and Biotechnology 53, 495-508.

Chen DW, Zentmyer GA, 1970. Production of sporangia by Phytophthora cinnamomi in axenic culture. Mycologia 2, 397-402.

Demeulenaere N, Höfte M, 2000. Influence of several surfactants on various asexual stages in the life cycle of two Phytophthora species. In: Proceedings of the Brighton Crop Protection Conference: Pests and Diseases 2000. Farnham, UK: BCPC Publications, 257-60.

Folman LB, Postma J, van Veen JA, 2003. Characterisation of Lysobacter enzymogenes (Christensen and Cook 1978) strain 3.1T8, a powerful antagonist of fungal diseases of cucumber. Microbiological Research 158, 107-15.

Forlot P, Harranger J, Payen J, Schwinn FJ, 1966. Phytophthora cryptogea Pethybr. et Laff., nouvel agent de la pourriture des endives (Cichorium intybus L. var. foliosum Hegi) en cours de forçage. Phytopathologische Zeitschrift 56, 1-18.

Kim BS, Lee JY, Hwang BK, 2000. In vivo control and in vitro antifungal activity of rhamnolipid B, a glycolipid antibiotic, against Phytophthora capsici and Colletotrichum orbiculare. Pest Management Science 56, 1029-35.

Lang S, Wullbrandt D, 1999. Rhamnose lipids - biosynthesis, microbial production and application potential. Applied

Microbiology and Biotechnology 51, 22-32.

Medina G, Juarez K, Soberon-Chavez G, 2003. The

Pseudomonas aeruginosa $\mathrm{rhl}$ B $\mathrm{B}$ operon is not expressed 
during the logarithmic phase of growth even in the presence of its activator RhlR and the autoinducer N-butyrylhomoserine lactone. Journal of Bacteriology 185, 377-80.

Nielsen TH, Christophersen C, Anthoni U, Sørensen J, 1999. Viscosinamide, a new cyclic depsipeptide with surfactant and antifungal properties produced by Pseudomonas fluorescens DR54. Journal of Applied Microbiology 86, 80-90.

Nielsen TH, Sørensen J, 2003. Production of cyclic lipopeptides by Pseudomonas fluorescens strains in bulk soil and in the sugar beet rhizosphere. Applied and Environmental Microbiology 69, 861-8.

Nielsen MN, Sørensen J, Fels J, Pedersen HC, 1998. Secondary metabolite- and endochitinase-dependent antagonism towards plant-pathogenic microfungi of

Pseudomonas fluorescens isolates from sugar beet rhizosphere. Applied and Environmental Microbiology 64, 3563-9.

Nielsen TH, Sørensen D, Tobiasen C, Andersen JB, Christophersen C, Givskov M, Sørensen J, 2002. Antibiotic and biosurfactant properties of cyclic lipopeptides produced by fluorescent Pseudomonas spp. from the sugar beet rhizosphere. Applied and Environmental Microbiology 68, 3416-23.

Pettitt TR, Wakeham AJ, Wainwright MF, White JG, 2002. Comparison of serological, culture, and bait methods for detection of Pythium and Phytophthora zoospores in water. Plant Pathology 51, 720-7.

Rahim R, Ochsner UA, Olvera C, Graninger M, Messner P, Lam JS, Soberon-Chavez G, 2001. Cloning and functional characterization of the Pseudomonas aeruginosa rhlC gene that encodes rhamnolsyltransferase 2, an enzyme responsible for di-rhamnolipid biosynthesis. Molecular Microbiology 40, 708-18.

Ron EZ, Rosenberg E, 2001. Natural roles of biosurfactants. Environmental Microbiology 3, 229-36. de Souza JT, de Boer M, de Waard P, van Beek TA, Raaijmakers JM, 2003. Biochemical, genetic, and zoosporicidal properties of cyclic lipopeptide surfactants produced by Pseudomonas fluorescens. Applied and Environmental Microbiology 69, 7161-72.

Stanghellini ME, Kim DH, Rasmussen SL, Rorabaugh PA, 1996a. Control of root rot of peppers caused by Phytophthora capsici with a nonionic surfactant. Plant Disease 80, 1113-6.

Stanghellini ME, Kronland WC, 1982. Root-rot of chicory caused by Phymatotrichum omnivorum and Phytophthora cryptogea. Plant Disease 66, 262-3.

Stanghellini ME, Miller RM, 1997. Biosurfactants: their identity and potential efficacy in the biological control of zoosporic plant pathogens. Plant Disease 81, 4-12.

Stanghellini ME, Nielsen CJ, Kim DH, Rasmussen SL, Rorabaugh PA, 2000. Influence of sub- versus top-irrigation and surfactants in a recirculating system on disease incidence caused by Phytophthora spp. in potted pepper plants. Plant Disease 84, 1147-50.

Stanghellini ME, Rasmussen SL, 1994. Hydroponics - a solution for zoosporic pathogens. Plant Disease 78, 1129-38.

Stanghellini ME, Rasmussen SL, Kim DH, Rorabaugh PA, 1996b. Efficacy of nonionic surfactants in the control of zoospore spread of Pythium aphanidermatum in a recirculating hydroponic system. Plant Disease 80, 422-8.

Thrane C, Nielsen TH, Nielsen MN, Sørensen J, Olsson S, 2000. Viscosinamide-producing Pseudomonas fluorescens DR54 exerts a biocontrol effect on Pythium ultimum in sugar beet rhizosphere. FEMS Microbiology Ecology 33, 139-46.

Tomlinson JA, Faithfull EM, 1979. Effects of fungicides and surfactants on the zoospores of Olpidium brassicae. Annals of Applied Biology 93, 13-9.

Tomlinson JA, Faithfull EM, 1980. Studies on the control of lettuce big-vein disease in recirculated nutrient. Acta Horticulturae 98, 325-32. 